\title{
«ФИНАНСОВЫЙ» ХАРАКТЕР СОБСТВЕННОСТИ НА СРЕДСТВА ПРОИЗВОДСТВА В СССР И КРИЗИС СОВЕТСКОЙ ЭКОНОМИКИ
}

\section{(c) 2020 Лебедев Константин Николаевич}

доктор экономических наук, доцент, профессор Департамента экономической теории Финансовый университет при Правительстве Российской Федерации, Россия, Москва

E-mail: KNLebedev@fa.ru

ORCID: https://orcid.org/0000-0002-4846-8097

В статье дается характеристика финансовой и нефинансовой разновидностей системы наделения предприятий собственными средствами, обосновывается большая эффективность нефинансовой разновидности, рассматривается характер соответствующих систем ресурсообеспечения у различных организационно-правовых форм предприятий, изучается политика советского государства в отношении развития тех или иных форм хозяйствования в городе и на селе, делается вывод о том, что после смерти И.В.Сталина в 1953 г., когда началось прогрессирующее замедление советской экономики, завершившееся ее кризисом, советское руководство необоснованно отдавало приоритет развитию относительно неэффективных финансовых форм хозяйствования.

Ключевые слова: финансы, нефинансы, система ресурсообеспечения, нефинансовая капитальная система, квазигосударственное предприятие, производственный кооператив.

Данная статья написана в рамках такого направления экономико-теоретического исследования, как нефинансовая экономика (экономика без финансов). Нефинансовая экономика рассматривает социально-экономическое развитие через призму конкуренции между альтернативными финансовыми и нефинансовыми системами его обеспечения («финансами» и «нефинансами»). Соответственно, она исходит из того, что у всех финансовых (основанных на трансфертных сделках) систем обеспечения (кредитных, налоговых, пенсионных, страховых и т.д.) имеются нефинансовые (основанные на товарообменных сделках) заменители [15, с. 46], например, банковский потребительский кредит заменяется «исламским» потребительским кредитом, когда банк покупает нужную клиенту вещь и перепродает ее клиенту с отсрочкой (рассрочкой) платежа. При этом под финансовыми системами обеспечения понимаются и неденежные системы трансфертного ресурсного обеспечения, например, зерновой кредит, осуществление взносов в уставный капитал оборудованием.

Нефинансовая экономика отмечает наличие в мире тенденции вытеснения финансов нефинансами, а внутри финансов - денежных финансов неденежными, что это происходит зачастую при активной государственной поддержке, хотя и в определенной мере непоследовательной, и объясняет этот процесс большей, при прочих равных условиях, приемлемостью (экономичностью, доступностью и безопасностью) нефинансовых, а внутри финансовых - неденежных, систем обеспечения для обслуживаемых ими клиентов (для решения их проблем), да и для самих ресурсодателей, по сравнению с нефинансовыми (денежными финансовыми). Так, исламский потребительский кредит обходится клиенту дешевле, чем банковский, в частности, за счет того, что покупателем нужного клиенту товара выступает банк, а не сам заемщик, склонный переплачивать за товар, приобретаемый за кредитные деньги [6, с. 56]. И в последние десятилетия исламский кредит вытесняет традиционный банковский кредит, о чем говорит бурный рост активов исламских банков - с середины 1990-х гг. по 2015 г. в среднем на 10-15\% в год. Ожидается, что в дальнейшем активы исламских банков будут расти в 2 раза быстрее, чем активы обычных банков [4, с. 61].

Нефинансовая экономика отмечает нелинейность процесса вытеснения финансов нефинансами при решении каких-то проблем. Торможение относительного развития и даже исчезновение альтернативных нефинансовых систем обеспечения объясняется явным или неявным противодействием, оказываемым развитию нефинансов финансовыми альтернативами, прежде всего, через регулирующее нефинансовые системы законодательство. Так, 
в России тормозится развитие исламского банкинга (под которым мы понимаем не исламизированный институт, а соответствующую нефинансовую систему экономических отношений), что, очевидно, неслучайно для страны с ростовщическо-ссудной моделью финансов [17, с. 75$]$. Причина торможения - «недоработанность» нормативно-правовой базы, которая при этом упорно недорабатывается уполномоченными органами, например в 2017 г. Комитет Государственной Думы по финансовому рынку отклонил законопроект о снятии с банков моратория на занятие коммерцией, что необходимо для развития исламского кредита [17, с. 78]. Неслучайно и внедрение исламского банкинга в России упорно связывается с исламизацией банковской сферы, а за ней - и других сфер [17, с. 79], заведомо неприемлемой для нашей страны, как будто товарообменные альтернативы кредиту не могут функционировать без религиозной формы.

Очевидно, что искусственное, т.е. не основанное на экономическом расчете, сдерживание государством развития нефинансовых систем ресурсообеспечения, как более эффективных, чем их финансовые альтернативы, связано с потерей общественного благосостояния. Цель настоящей статьи - показать, что неуклонное замедление советской экономики по сравнению с мировой, завершившееся ее кризисом, вызвавшим гибель страны, было связано с экономически необоснованным приоритетным развитием советским государством в целом финансового элемента системы наделения предприятий собственными средствами при их создании и расширении (системы ресурсообеспечения «капитал»).

Для финансовой, т.е. основанной на трансфертных сделках, «капитальной» системы обеспечения характерно то, что учредители предприятия (пайщики, члены) в обмен на имущественные взносы (деньги, оборудование и т.д.) получают в собственность свидетельства о взносах, например акции (фиктивный капитал), тогда как взносы переходят в собственность самого предприятия, а для нефинансовой, т.е. основанной на товарообменных сделках - то, что учредители предприятия в обмен на имущественные взносы получают в собственность именно имущество предприятия (физический капитал), которым владеют на праве общей (долевой и/или совместной) собственности. В первом случае потребность в особом собственнике имущества, объединяемого учредителями, и желание последних быть собственниками именно фиктивного капитала, обусловлены тем, что учредители не желают связывать себя какими-либо реальными заботами о дальнейшей судьбе предприятия (лично участвовать во всех его делах, гасить его долги из своего имущества и т.д.), требующимися от собственника любой вещи, рассчитывая на получение, хотя и относительно низкого, но не связанного с затратой особых усилий, дохода на вложенный капитал. Во втором случае особый собственник для объединяемого имущества не требуется, так как учредители сами собираются непосредственно управлять предприятием, даже участвовать в его деятельности личным производственным трудом, как учредители производственных кооперативов или индивидуальных предприятий, намерены отвечать по долгам предприятия сверх осуществленных учредительских взносов и т.д., рассчитывая, естественно, на получение значительно более солидного дохода от этого предприятия. Следует отметить, что в первом случае предприятие, в собственность которого переходят взносы учредителей, могут образовать один или несколько учредителей, пожелавших или изначально имевших намерение непосредственно вести соответствующее коммерческое предприятие.

В случае, когда учредителем предприятия является государство (все общество), также возможны два варианта его собственности - нефинансовый финансовый. В случае, если государство непосредственно управляет деятельностью предприятия, что выглядит как разработка и утверждение ему всех плановых показателей деятельности и строгий контроль за их выполнением, обеспечивает его государственными заказами, централизованным материальнотехническим, кадровым и прочим снабжением (аналог участия члена производственного кооператива в деятельности предприятия личным трудом), то оно само является собственником имущества предприятия. В случае, когда государство отказывается от такого участия в дальнейшей судьбе учрежденного им предприятия, т.е. предоставляет предприятию хозяйственную самостоятельность, то государство становится собственником его уставного капитала, а собственником имущества предприятия становится само предприятие (фактически - его наем- 
ные работники).

При соответствии организационно-правовой формы предприятия содержанию его реальных экономических отношений финансовыми являются капитальные системы таких известных в современной России форм хозяйствования, как акционерное общество (АО) и общество с ограниченной ответственностью (ОоO), нефинансовыми - таких как индивидуальное предприятие (ИП), полное товарищество, простое товарищество, производственный кооператив (ПК). Во времена СССР нефинансовой формой хозяйствования на селе выступал колхоз, представлявший собой сельскохозяйственный производственный кооператив. Вначале колхозы существовали в форме коммун, где обобществлялось все имущество пайщиков; далее - товариществ по совместной обработке земли (ТОЗов), где обобществлялась земля (точнее - землепользование); затем - сельхозартелей, т.е. собственно колхозов, где обобществлялось все производственное имущество, кроме относившегося к личному подсобному хозяйству [13]. Что касается государственного предприятия (ГП) в СССР, в частности альтернативной колхозу формы крупного хозяйствования на селе совхоза, то оно в периоды истории СССР, когда управление государственными предприятиями было централизованным (административнокомандным, плановым), выступало нефинансовой формой хозяйствования (имело финансовую капитальную систему), а в периоды, когда предприятиям предоставлялась хозяйственная самостоятельность - финансовой (имело финансовую капитальную систему). Последнюю разновидность государственного предприятия как организационно-правовой формы назовем квазигосударственным предприятием (КП). Заметим, что ГП и КП являются альтернативными формами хозяйствования (с точки зрения капитальной системы) просто-напросто потому, что в СССР одни и те же предприятия действовали в форме то ГП, то КП, в зависимости от того, какую политику собственности на имущество госпредприятий проводило советское государство в тот или иной период хозяйственной истории страны (см. ниже).

Как и любые нефинансовые альтернативы, нефинансовые формы хозяйствования, согласно нефинансовой экономике, являются более эффективными, прежде всего более экономичными (более дешевыми по вложениям на еди- ницу выпуска), чем финансовые. Для целей настоящего исследования требуется обоснование большей эффективности ГП и ПК по сравнению с КП. Большая экономичность ГП по сравнению с КП объясняется большей заботой об имуществе предприятия, которую проявляет собственникгосударство по сравнению с собственникомколлективом наемных работников предприятия. Повышенная заботливость об имуществе предприятия собственника-государства, в свою очередь, объясняется тем, что государство, за то, чтобы стать собственником имущества предприятия, платило реальные средства (вносило деньги, оборудование и т.д.), а наемным работникам предприятия соответствующее имущество досталось в собственность практически бесплатно - предприятие расплатилось с учредителями за это имущество фиктивным капиталом (акциями и т.д.), т.е. вещами, внутренняя стоимость которых по сравнению со стоимостью полученных взносов ничтожна. Как и любые вещи, не заработанные личным трудом, например купленные на кредитные, бюджетные, выигранные в лотерею и т.п. деньги, полученное бесплатно имущество предприятия ценится его получателями значительно меньше, чем заработанное имущество. Эта пониженная ценность имущества предприятия в глазах наемных работников находит проявление в менее эффективном управлении им. Кстати, ценность соответствующего имущества не повышается в случае, если такое управление наносит ущерб окружающим в виде долгов предприятия, которое то не может вовремя погасить, поскольку наемные работники не обязаны оплачивать долги предприятия.

Одним из признаков низкоэффективного управления выступает приоритет в расходовании средств предприятия на потребление, а не на накопление, или, по-другому, приоритет социального развития предприятия, а не его производственного (в том числе научно-технологического) развития. Приоритет социального развития, свойственный, таким образом, КП, приводит к замедлению производственного развития предприятия по сравнению с его развитием в условиях, когда собственником имущества предприятия является государство, заплатившее за него реальные средства и, соответственно, ценящее его больше и более эффективно управляющее им, проявлением чего является, в частности, приоритет производственного развития предприятия над его соци- 
альным развитием. Он и приводит к повышению экономичности выпуска (он же приводит к ускорению социального развития предприятия в долгосрочной перспективе), в связи с чем ГП и является более эффективной формой хозяйствования, чем КП.

О приоритете социального развития для государственного предприятия, получившего хозяйственную самостоятельность, т.е. имеющего форму КП, лучше всего говорит история позднего СССР - в виде приоритета для государственных предприятий, получивших тогда абсолютную хозяйственную самостоятельность (переведенных на полный хозрасчет), наполнения фондов заработной платы, материального поощрения и социального развития по сравнению с фондами производственного и научно-технологического развития. О нем говорят данные о взрывном росте номинальных денежных доходов населения после перевода советских предприятий с 1988 г. на полный хозрасчет, т.е. когда наемные работники поняли, что фактически получили право устанавливать зарплату самим себе. Годовые денежные доходы населения в 1986-1990 гг. представляли собой следующий ряд: 436,3, $452,1,493,5,558,0$ и 652,5 млрд. руб. [20]. Если в 1987 г. по сравнению с предыдущим годом они выросли только на 4\% $(452,1 / 436,3 * 100)$, то в 1988 - уже на $9\left(493,5 / 452,1^{*} 100\right)$, в 1989 - на 13 (558,0/493,5*100), а в 1990 г.- вообще на 17\% (652,5/558,0*100). Приоритет потребления по сравнению с накоплением характерен для наемных работников государственных предприятий и в условиях централизованного управления последними, но он нейтрализуется необходимой массой директивных показателей, обеспечивающих приоритет производственного (в том числе научно-технологического) развития предприятий, и строгим контролем государства за их выполнением.

Более высокая эффективность управления имеет и другие проявления, отражающиеся на эффективности деятельности предприятия, например, приоритет долгосрочного развития над краткосрочным, в целом долгосрочный характер планирования. Большая эффективность ГП по сравнению с КП объясняется и тем, что государственные предприятия в условиях централизованного управления обеспечиваются гарантированными госзаказами и централизованным снабжением.

Большая экономичность ПК по сравнению с
КП объясняется, прежде всего, как и в случае с ГП, большей эффективностью управления имуществом предприятия со стороны «нефинансового» собственника имущества предприятия, т.е. собственника, реально заплатившего за это имущество, так как собственниками имущества ПК также являются его учредители, заплатившее за него реальные средства. Однако ПК обладает дополнительным фактором большей экономичности (эффективности) по сравнению с КП, которым не обладает ГП. Дело в том, что, в отличие от КП, собственниками, заплатившими за имущество реальные средства, являются и лица, осуществляющие на предприятии и производственную деятельность, каковыми являются учредители ПК. Это придает им дополнительный мощный импульс к производительному труду и бережливому отношению к имуществу предприятия по сравнению с наемными работниками КП, осуществляющими производственную деятельность, которые являются «финансовыми» собственниками имущества.

Кстати, для ПК в условиях развитого кооперативного сектора также характерно обеспечение ПК централизованными заказами и снабжением, которые осуществляют ассоциированные с данным ПК другие ПК, а также сбытовые, снабженческие и пр. кооперативы.

Важно отметить, что наемным работникам отношение к имуществу предприятия «как к своему», проявляющееся в большей эффективности их как производственной, так управленческой деятельности, невозможно привить записями в законодательстве или уставных документах предприятия об их собственности на его имущество. Его можно привить, лишь заставив наемных работников реально заплатить за имущество предприятия, как вариант - назначить выкупные платежи за доли в его имуществе, или путем убедительного доказывания работникам, что им недоплачивали законную заработную плату, и перед ними у владельцев предприятия накопился долг, равный стоимости имущественного комплекса предприятия.

Политика советского руководства в отношении развития таких альтернативных форм хозяйствования, как государственное и квазигосударственное предприятие (в том числе на селе), менялась несколько раз, и в ней можно выделить 4 периода. В 1917-1920 гг., т.е. после Октябрьской революции 1917 года до перехода к Новой экономической политике (НЭПу) в 1921 г., 
в стране формировалась и развивалась система государственных предприятий с централизованным управлением. Государственные предприятия формировались, прежде всего, путем национализации предприятий разных отраслей (промышленности, транспорта, сельского хозяйства, банковской сферы и т.д.), находившихся в частной собственности (в собственности АО, паевых товариществ и пр.) [3]. Централизованная система управления промышленностью во главе с Высшим советом народного хозяйства (BCHX), так называемый главкизм, была сформирована к концу 1918 г. Вся работа по планированию, распределению заказов и перераспределению готовой продукции, снабжению, в том числе ресурсом «труд» на основе трудовой повинности, в частности в форме создания трудовых армий из резервистов и «нетрудовых элементов», была сконцентрирована в главках ВСНХ [30]. Соответственно, государство сосредоточилось на развитии такой формы хозяйствования, как нефинансовое государственное предприятие.

В 1921-1928 гг. (в период НЭПа) наиболее эффективные и крупные государственные предприятия объединяются в тресты, которым предоставляется хозяйственная самостоятельность (трест становится основной производственной единицей). Тресты самостоятельно решают, что производить и где реализовывать товары, входящие в них предприятия снимаются с государственного снабжения и закупают нужные им товары на рынке. Одновременно упраздняются главки ВCHХ (главкизм), а их функции передаются на места районным управлениям и губернским совнархозам [22]. Отменяется принудительный труд и вводится рынок труда [27]. Таким образом, в период НЭПа государство развивало такую альтернативную государственному объединению предприятий (как объекту централизованного управления предприятиями) форму хозяйствования, как финансовое квазигосударственное объединение предприятий, которая, с точки зрения нефинансовой экономики, является менее эффективной формой хозяйствования. Следует отметить, что, несмотря на передачу части государственных предприятий, прежде всего мелких и средних, в частные руки, оставшиеся государственные предприятия представляли подавляющую часть экономики в городе, в частности они производили $92,4 \%$ промышленной продукции (частные предприятия $4,9$, ПК $-2,7)$ [22], что говорит о существенном влиянии на экономику страны перехода к финансовой форме государственного хозяйствования. В этот же период советское руководство реанимирует такую финансовую форму крупного хозяйствования, как АО. Первым АО, учрежденным в Советской России, с участием как госструктур (ВСНХ, Центросоюз, Наркомвнешторг), так и частных лиц, стало Акционерное общество внутренней и вывозной торговли кожевенным сырьем «Кожсырье» [3]. На начало 1925 г. в промышленности, торговле и банковской сфере [1] было создано $150 \mathrm{AO}$ [2].

Совершенный в годы НЭПа переход к менее эффективным, финансовым формам крупного хозяйствования не сыграл роковой роли в судьбе отечественной экономики и страны в целом, возможно потому, что соответствующий курс в области форм хозяйствования был своевременно пересмотрен. На период НЭПа пришлось послевоенное и послереволюционное восстановление экономики в нашей стране, которое происходило быстрее, чем в других странах. Если у нас этот период занял 3-5 лет, то в Германии и Франции - 10 лет. Но при этом восстановление экономики у нас происходило на старой технической и организационной основе, когда, например, в промышленности рост производства происходил за счет ввода в строй оборудования, остановленного или поврежденного во времена войн и революций [22], что консервировало ее отсталость.

В 1929-1953 гг. в стране вновь действует и развивается система централизованного управления государственными предприятиями, в ряды которых в самом начале это периода вливаются созданные в период НЭПа частные предприятия, в том числе АО [2]. В связи с этим финансовая квазигосударственная форма хозяйствования вновь трансформируется в нефинансовую государственную форму, характеризующуюся, с точки зрения нефинансовой экономики, большей эффективностью. Административно-командная государственная экономика с нефинансовыми отношениями собственности процветает в СССР в городе до самой смерти И.В.Сталина в 1953 г. Соответствующий период жизни страны является периодом резкого взлета ее экономики (разумеется, с учетом особенностей военного периода), причем опережающего роста по сравнению с ростом мировой экономики в целом и экономик почти всех ведущих стран мира. За 10 лет с 1929 г. промышленное производство в СССР 
увеличилось в 4,8 раза, тогда как промышленное производство капиталистических стран в 1938 г. составило 93\% от уровня 1929 г. [26, с. 32]. Темпы роста производительности труда в промышленности в 1929-1937 гг. в СССР были в 2 раза больше, чем в капиталистическом мире. Если в СССР в 1937 г. она составила 203\% от уровня 1929 г., то в капиталистических странах - 104\%, в частности в США - 97, Англии и Германии - 110, Франции - 92, Италии - 95 [26, с. 38].

1954-1990 гг. являются периодом поэтапного демонтажа централизованной системы управления государственными предприятиями и развития их хозяйственной самостоятельности. В начале этого периода происходит резкое сокращение числа показателей народнохозяйственного плана. Если в 1953 г. их было 9490 (в 19404744), то в 1954 г. их число сократилось до 6308, в 1957 - до 3390, в 1958 - до 1780. С 1953 г. началось сокращение контрольных функций государства в отношении экономики (экономического контроля со стороны МВД, Министерства государственного контроля, прокуратуры и др.) [28]. С точки зрения нефинансовой экономики, это не могло не сказаться негативно на эффективности государственных предприятий, организационно-правовая форма которых стала трансформироваться из нефинансового государственного предприятия в финансовое квазигосударственное, подталкивая к такой же трансформации реальные экономические отношения на предприятиях. Но, очевидно, запас эффективности нефинансового государственного хозяйствования был таков, или инерция реальных экономических отношений в государственной экономике оказалась такой, что в расчете на все десятилетие 1950-х гг. темп роста производительности труда в советской экономике еще находился на уровне развитых капиталистических стран. В 1951-1960 гг. производительность труда в промышленности выросла у нас на 46\%, тогда как в США - только на 34, а в Великобритании на $22 \%$, но в ФРГ - на 53, а во Франции - на 59\% [28]. И в целом 1950-е гг. оказались десятилетием опережающего, по сравнению с общемировым, роста российского ВВП. Если в 1950 г. доля СССР в мировом ВВП составляла 11,12\%, то в 1960 г. она достигла рекордных 14,47\% [5].

Очевидно, существенным шагом в демонтаже института централизованного управления и развитии института хозяйственной самостоятельности государственных предприятий, ускорившим трансформацию нефинансовой государственной формы хозяйствования в финансовую квазигосударственную, стали «косыгинские» реформы, проводившиеся в 1965-1970 гг. Их сутью было сокращение количества директивных плановых показателей, спускаемых предприятиям, и превращение в ключевые показатели деятельности предприятий рентабельности и прибыли [14]. Это - наглядная картина того, как превращение государственного управления предприятиями во все более косвенное сопровождается превращением государства во владельца их уставного капитала, реально интересующегося только прибылью и рентабельностью вложенных средств. Обусловленная этим шагом дальнейшая трансформация государственного хозяйствования в неэффективное квазигосударственное хозяйствование привела к тому, что в 1960-е гг. началось отставание развития советской экономики от развития мировой экономики, продолжившееся и в 1970-е гг. В 1970 г. доля СССР в мировом ВВП упала до $13,18 \%$, а в 1980 - до 11,71 [5]. Это отставание еще более ускорилось в связи с принятием в 1987 г. Закона о государственном предприятии (объединении), который, по мнению экспертов, радикально увеличил степень самостоятельности предприятий и столь же радикально сократил контроль за экономикой со стороны государства. Обусловленное этим законом перераспределение предприятиями ресурсов в пользу текущего потребления (см. выше) привело не только к обострению положения на потребительском рынке (так, мясо, масло, сахар и пр. стали отпускаться по талонам), но и к резкому сокращению инвестиций в развитие производства и спаду в важнейших отраслях народного хозяйства, что ускорило кризис советской экономики [12].

Заметим, что в самом конце рассматриваемого периода государство делает ставку и на такие финансовые формы хозяйствования, как $\mathrm{AO}$ и ООО - Постановлением Совета Министров СССР от 19.06.1990 № 590 принимается Положение об акционерных обществах и обществах с ограниченной ответственностью [3]. Превращение хозяйственной самостоятельности государственных предприятий в абсолютную, т.е. полное перерождение государственного предприятия в финансовое квазигосударственное, ускорило замедление экономики СССР. В 1990 г. доля СССР в мировом ВВП упала до 9,22\% [5]. Если за 1970-е гг. эта доля сократилась на 11\% 
(100-11,71/13,18*100), то за 1980 -е - на $21 \%$ (100-9,22/11,71*100).

Далее, рассмотрим политику советского государства в отношении такой нефинансовой формы хозяйствования, как производственный кооператив (ПК). В ней можно выделить три периода. 1917-1953 гг., т.е. период до смерти И.В. Сталина, можно назвать периодом государственной поддержки и терпимого отношения к ПК, создаваемым крестьянами и кустарями. Если на начало этого периода, судя по данным о классовом составе населения за 1913 г., ПК как форма хозяйствования практически отсутствовала, то в 1928 г. колхозное крестьянство и кооперированные кустари составляли $2,9 \%$ населения, а 1937 г. $-57,9$ [18, с. 19]. При этом в 1937 г. из 57,9\% производственно-кооперативного населения 44,9 процентных пункта образовывало колхозное крестьянство [21], из чего можно заключить, что к несельскохозяйственным ПК, т.е. кооперированным кустарям, в том году относилось целых 13,7\% населения $(57,9-44,9)$ СССР. В последующие годы данного периода доля населения, относящегося к ПК, сокращалась, упав в 1955 г. до 41,2\% [18, с. 19], но происходило это вследствие массового исхода сельского населения, основная масса которого относилась к колхозному крестьянству, в города - доля населения, занятого в сельском хозяйстве, сократилась с $68,4 \%$ в 1940 г. до $56,6 \%$ в 1956 г. [18, с. 17].

1954-1980 гг. являются годами гонений на ПК, постепенно ослабевавших к концу этого периода. Наиболее активные гонения на ПК происходят в годы правления Н. С.Хрущева, сменившего И.В. Сталина у руля государства. Начатая еще в 1950 г. при И.В.Сталине политика объединения «слабых» колхозов [7, с. 161] при Н.С.Хрущеве превратилась в политику реорганизации объединенных и даже «сильных» колхозов в совхозы. Так, в период 1957-1964 гг. 20254 колхоза были преобразованы в 4880 совхозов [8]. В 19581961 гг. в специализированные совхозы было реорганизовано большое количество пригородных колхозов, многие из которых были сильными [29, с. 152]. В 1950-е гг. колхозы принудили выкупить технику обслуживавших их машиннотракторных станций, что в значительной мере подорвало их финансовое состояние [25]. Новые сельскохозяйственные предприятия создавались в форме совхоза. В результате борьбы с колхозной формой хозяйствования и развития его совхозной формы с 1954 г. по 1980 г. число кол- хозов сократилось с 89,0 тыс. [18, с. 128$]$ до 25,9 [19, с. 277], а число совхозов увеличилось с 4,9 тыс. [18, с. 135] до 21,1 [19, с. 286], валовая продукция сельского хозяйства совхозов стала превышать таковую колхозов, например, в 1980 г. первая составила 44,8 млрд. руб., тогда как вторая - 41,8 млрд. руб. [19, с. 277, 286].

Гонениям подверглась и несельскохозяйственная производственная (промысловая) кооперация, например, в связи с выходом Постановления ЦК КПСС и Совета Министров СССР от 14 апреля 1956 г. «О реорганизации промысловой кооперации». К его выходу в стране действовало 114 тыс. предприятий промысловой кооперации, на которых было занято 1,8 млн. чел., производивших 6,9\% промышленной продукции страны (в частности 70\% металлической посуды, 40 - мебели, 1/3 верхнего трикотажа и почти все игрушки) [10]. «Приговором» сектору ПК фактически выступило принятие XXII съездом КПСС в 1961 г. новой (третьей) Программы КПСС, согласно которой в 1980 г. должен завершиться процесс перехода к единой общенародной форме собственности (т.е. к государственному предприятию) в связи с созданием материально-технической базы коммунизма, построением в СССР в основном коммунистического общества [23]. Промысловая кооперация к 1970 г. была вообще ликвидирована, а доля занятых в общественном хозяйстве колхозов (и в личном подсобном хозяйстве) в общей численности занятых сократилась с 30,1\% в 1960 г. до 16,2 в 1970 и до 11,0 в 1980 [19, с. 390]. Таким образом, в 1980 г. производственно-кооперативный сектор в нашей стране сократился до $11 \%$ экономики (по доле занятых в ней).

1981-1990 гг. являются годами терпимого отношения к ПК, ближе к концу данного периода превратившимися в годы их активной поддержки. Прежде всего, в этом периоде начинает расти число колхозов, причем оно растет даже быстрее, чем число совхозов, также продолжившее свой рост. Число колхозов в 1990 г. составило 29,1 тыс. [20], увеличившись за 10 лет на $12 \%(29,1 / 25,9-$ $1 * 100)$. Число совхозов в том же году составило 23,5 тыс. [20], увеличившись за те же годы на $11 \%$ $(23,5 / 21,1-1 * 100)$, т.е. менее значительно.

В рассматриваемом периоде советское государство делает ставку на ПК в развитии экономики в городе. В феврале 1987 г. Совет Министров СССР принял ряд постановлений, нацеленных на развитие кооперации, прежде всего промыс- 
ловой. И уже к июлю 1987 г. в СССР действовали 9124 промысловых кооператива, в том числе 1332 - по производству потребительских товаров, 3878 - по бытовому обслуживанию населения, 2016 - общественного питания, 347 - по сбору и переработке вторсырья. М.С.Горбачев (последний лидер СССР) надеялся на то, что в стране появятся высокоэффективные и хорошо технически оснащенные промысловые кооперативы, способные производить продукцию и услуги высшего качества и конкурировать с зарубежными и отечественными предприятиями М. С. Горбачев [11].

В 1990 г. доля населения, занятого в колхозах (без занятых в личном подсобном хозяйстве) составила $8,4 \%$, а в кооперативах по производству товаров и услуг $-3,2 \%$ [20], т.е. в секторе ПК в целом - $11,6 \%(8,4+3,2)$. Несмотря на огромные темпы роста промысловой кооперации, она не успела занять сколь-нибудь существенное место в экономике страны до момента ее гибели. При этом в 1990 г. основная масса занятого населения приходилась на государственный сектор экономики $-81,6 \%$, а без концернов, хозяйственных ассоциаций, арендных предприятий и AO - 78,3\% [20], который к концу рассматриваемого периода имел яркий квазигосударственный характер.

Таким образом, в период после смерти И.В.Сталина, т.е. в 1954-1990 гг., когда экономика СССР последовательно замедлялась, что в итоге привело ее к кризису, вызвавшему распад страны, советское государство развивало в целом финансовые формы хозяйствования, прежде всего финансовое квазигосударственное предприятие, характеризующиеся более низкой эффективностью, чем их нефинансовые альтернативы, большую часть этого периода, а именно в 1954-1980 гг., вело борьбу с такой нефинансовой формой хозяйствования, как ПК. При этом данная политика в отношении форм хозяйствования была необоснованной не только с точки зрения теории нефинансовой экономики, но и с точки зрения марксистской экономической теории, выступавшей теоретической основой экономической программы КПСС. Что касается политики в отношении государственного предприятия, то в программных документах коммунистической партии было записано требование создания государственной экономики с централизованным управлением, или, что то же самое, государственной плановой экономики. В
«Манифесте коммунистической партии» (1848), написанном К. Марксом и Ф.Энгельсом, зафиксировано требование вырвать у буржуазии весь капитал, централизуя его в руках государства [16, с. 446], в Программе РСДРП (1903) содержится требование замены частной собственности на средства производства и обращения общественной (т.е. государственной.- примеч. автора) и введения планомерной организации общественно-производительного процесса [24], т.е. ни о какой хозяйственной самостоятельности государственных предприятий в этих документах речи не шло. Что же касается ПК, то «поздние» основоположники марксизма предложили и «кооперативный» путь ликвидации частной собственности и перехода к коммунизму - путем создания самоуправляющихся коммун, кооперативных фабрик и т.д., т.е. ПК, самостоятельно формирующих негосударственные органы народнохозяйственного управления (ассоциации, союзы и т.д.) [8].

Причина, вызвавшая после смерти И.В.Сталина отказ руководства страны от централизованной системы управления государственными предприятиями, ясна из работы Г.И.Ханина (Ханин, 2002). Как отмечает Г. И. Ханин, Н. С. Хрущев возглавлял борьбу партийных деятелей с хозяйственными деятелями за руководство экономикой страны и другими областями социальной жизни, в которой при И.В.Сталине побеждали хозяйственные деятели, в частности ее кульминацией стал июньский пленум ЦК КПСС 1957 года, на котором победили Н.С.Хрущев и его сторонники. Сокращение же директивных показателей, прежде всего натуральных, и контрольных функций государства в экономике, к чему сводились первые шаги предоставления хозяйственной самостоятельности государственным предприятиям, было выгодно хозяйственной номенклатуре, желавшей бесконтрольности для приукрашивания дел и личного обогащения [28]. Очевидно, стремление хрущевской группировки заручиться поддержкой широких слоев хозяйственной номенклатуры на низах для обеспечения победы в борьбе с высшим хозяйственным руководством страны и стало причиной предоставления предприятиям хозяйственной самостоятельности. Таким образом, в основе политики демонтажа централизованной системы управления государственными предприятиями лежал не экономический, а политический расчет. В основе политики борьбы с такой формой 
хозяйствования, как ПК, также лежал не экономический, а политический расчет, правда, долгосрочный. Как уже отмечалось выше, кооперативный путь перехода к коммунизму связан с самостоятельным формированием кооперативами негосударственных органов народнохозяйственного управления. В связи с этим развитие государством такой формы хозяйствования, как ПК, равносильно формированию собственными руками абсолютно неподконтрольной ему экономики, что означает утрату коммунистической партией экономической власти в стране, от чего недалеко до утраты и политической власти.

Таким образом, показано, что замедление экономики СССР, начавшееся в конце 1950-х гг. и завершившееся ее кризисом, было вызвано экономически необоснованной государственной политикой приоритетного развития относительно неэффективных финансовых форм хозяйствования, в связи с чем представлен более широкий взгляд на формы хозяйствования как на причины этого замедления, и дано более общее объяснение их разнонаправленной роли в данном процессе - принадлежность форм хозяйствования к финансам или отсутствие таковой. Концепция финансовых и нефинансовых форм хозяйствования может быть использована в качестве теоретической основы для разработки соответствующей политики современного российского государства.

\section{Библиографический список}

1. Акционерное общество / booksite.ru URL: https://www.booksite.ru/fulltext/1/001/008/009/228.htm (дата обращения: 09.10.2020).

2. Акционерные общества и акционерное законодательство в начале XX в. / TEXTARCHIVE.RU. URL: https:// textarchive.ru/c-2702772-p2.html (дата обращения: 18.09.2020).

3. Акционерные общества и акционерное право в советский и постсоветский периоды / URL: https://studme. org/35028/pravo/aktsionernye_obschestva_aktsionernoe_pravo_sovetskiy_postsovetskiy_periody (дата обращения: 10.09.2020).

4. Антропов В. В. Исламские банки в мировой финансовой системе // Деньги и кредит. 2017. № 7. С. 57-64.

5. Болотин Б. М. Мировая экономика за 100 лет // Мировая экономика и международные отношения. 2009. № 9. С. $90-114$.

6. Будович Ю.И., Лебедев К. Н. Место финансов в современной экономике (Экономика без финансов).- Краснодар: НИИ экономики ЮФО, 2020. 187 с.

7. Васильев М.Неперспективные села и преобразование колхозов в совхозы в 1950-х - начале 1960-х гг. (по материалам Тамбовской области) // Власть. 2012. № 2. С. 161-164.

8. Верхогляд Д. А. Преобразование колхозов в совхозы в 1960-1970-х гг.: причины и влияние изменения статуса хозяйствующего субъекта на реализацию права землепользования // Юристъ-Правовед. 2013. № 6 (61). С. $116-119$.

9. Дьяченко В.И. Марксизм о первой (начальной) фазе коммунизма / Инициативная группа по формированию движения За Коммунистическое развитие в XXI веке. Из царства необходимости - в царство свободы. 05.02.2016. URL: http://communism21.org/abc/16 (дата обращения: 24.09.2020).

10. Елютин О. Кооперация в России - невостребованный опыт // Наука и жизнь. 2020. № 10. URL: https://www. nkj.ru/archive/articles/2887/ (дата обращения: 28.09.2020).

11. Кирсанов Р. Кооперативный бум. Какими были первые шаги к капитализму? / Живая история. 26.10.2017. URL: http://history.ru/statyi/kooperativnyj-bum (дата обращения: 15.09.2020).

12. Кирсанов Р.Г.Закон СССР о государственном предприятии: анализ правоприменительной практики // История государства и права. 2014. № 17. С. 3-6.

13. Кооперация в годы НЭПа и в последующий период / Studbooks.net. URL: https:/.net/1072763/ agropromyshlennost/kooperatsiya_gody_nepa_posleduyuschiy_period (дата обращения: 18.09.2020).

14. Косыгин и его реформы - суть и итоги / История России. URL: https:/historykratko.com/kosyginskayareforma (дата обращения: 21.10.2020).

15. Лебедев К. Н. Экономика без финансов // Вопросы экономики и права. 2018. № 6 (120). С. 45-53.

16. Маркс К., Энгельс Ф. Сочинения. Т. 4.- М.: Государственное издательство политической литературы, 1955. 616 (XIV) c.

17. Мокина Л. С. Исламское финансирование в России и в мире: проблемы и перспективы // Вестник Прикамского социального института. 2017. № 3 (78). С. 74-80.

18. Народное хозяйство СССР: Стат. сборник.-М.: Государственное статистическое издательство, 1956. 263 с. 
19. Народное хозяйство СССР в 1985 году: Стат. ежегодник.- М.: Финансы и статистика, 1986. 655 с.

20. Народное хозяйство СССР в 1990 г.-М.: Финансы и статистика, 1991. 750 с.

21. Народное хозяйство СССР в 1960 году. Статистический ежегодник.-М.: Госстатиздат ЦСУ СССР, 1961.943 с.

22. Нэп в народном хозяйстве / Studme.org. URL: https://studme.org/35985/istoriya/nep_narodnom_hozyaystve (дата обращения: 25.10.2020).

23. Программа Коммунистической партии Советского Союза. Принята XXII съездом КПСС в 1961 году (третья в истории Партии). URL: http://aleksandr-kommari.narod.ru/kpss_programma_1961.htm (дата обращения: 12.10.2020).

24. Программа Российской социал-демократической рабочей партии. 1903 г. / Музей истории российских реформ имени П.А.Столыпина. URL: http://xn - e1aaejmenocxq.xn - p1ai/node/13690 (дата обращения: 23.09.2020).

25. Реорганизация MTС в СССР в 1950-е годы / Илья Винштейн. URL: http://www.winstein.org/publ/36-1-0-3329 (дата обращения: 25.10.2020).

26. Социалистическое строительство Союза ССР (1933-1938 гг.): Стат. сборник.- М.- Ленинград: Госпланиздат, 1939. 208 с.

27. Стряпихина А.А. Государственная политика СССР в области занятости (20-е годы XX в.) // Труд и социальные отношения. 2011. № 3. С. 91-95.

28. Ханин Г.И. 50-е годы - десятилетие триумфа советской экономики / ИСТорические MATepиалы. URL: https://istmat.info/node/57531 (дата обращения: 19.10.2020).

29. Шлыкова О.В.Преобразование колхозов в совхозы в 1950-1960-е гг. // Вестник Саратовского государственного социально-экономического университета. 2008. № 3 (22). С. 152-156.

30. Экономическая политика советского государства (1917-1918 гг.) / Инфопедия для углубленных знаний. URL: https://infopedia.su/4x58d7.html (дата обращения: 15.09.2020). 